anales de psicología, 2016, vol. 32, $\mathrm{n}^{\circ} 2$ (mayo), 355-365 http://dx.doi.org/10.6018/analesps.32.2.216141
(C) Copyright 2016: Servicio de Publicaciones de la Universidad de Murcia. Murcia (España) ISSN edición impresa: 0212-9728. ISSN edición web (http://revistas.um.es/analesps): 1695-2294

\title{
Psychometric properties of the Spanish version of the Coping Strategies Inventory (CSI) in older people
}

\author{
Laura Rubio ${ }^{1}$, Cristina G. Dumitrache ${ }^{2}$, Eulogio Cordón-Pozo ${ }^{3}$, y Ramona Rubio-Herrera ${ }^{2}$ \\ ${ }^{1}$ Departamento de Ciencias de la Educación, Universidad de Burgos (España). \\ ${ }^{2}$ Departamento de Psicología Evolutiva y de la Educación, Universidad de Granada (España). \\ ${ }^{3}$ Departamento de Organización de Empresas, Universidad de Granada (España).
}

\begin{abstract}
Título: Propiedades psicométricas de la versión española del Inventario de Estrategias de Afrontamiento en personas mayores.

Resumen: El objetivo del estudio fue evaluar las propiedades psicométricas del Inventario de Estrategias de Afrontamiento (CSI) en personas mayores. Para ello, se administró el cuestionario a 243 personas con edades comprendidas entre los 55 y 99 años. Los resultados muestran una estructura factorial de primer orden similar a la de la versión original y la adaptación al castellano en población general. Además se observaron elevados niveles de consistencia interna y validez convergente en las diferentes estrategias primarias. Sin embargo, la escala Evitación de Problemas no superó el test de validez y fiabilidad por lo que se propone la eliminación de 2 de sus ítems. Por otro lado en este trabajo se confirma la estructura secundaria y terciaria del inventario obtenida en la versión original y que no se conseguía en los estudios de adaptación y replicación al castellano.
\end{abstract}

Palabras clave: CSI, afrontamiento, mayores, propiedades psicométricas, versión española.

\section{Introduction}

Coping strategies have been defined as those behaviors and cognitive abilities used by people to deal with internal and environmental demands that are perceived as stressful (Folkman, 1984; Lazarus \& Folkman, 1984). If individuals consider the situation to be meaningful to them and if they perceive their personal resources as ineffective or inadequate to solve it, the situation becomes stressful (Lazarus \& Folkman, 1984). Because the way in which a person copes with stressful situations determines the impact that these situations will have on his or her well-being, health and quality of life (Englbrecht et al., 2012; Gustems-Carnicers \& Calderón, 2013; Skinner, Edge, Altman, \& Sherwood, 2003) coping strategies constitute a relevant aspect of psychological functioning.

Several classifications have been proposed for coping strategies: active and passive coping, problem-focused or emotion-focused, approach or avoidance strategies and functional and dysfunctional coping (Carver, Scheier, \& Weintraub, 1989; Lazarus \& Folkman, 1984; Maddi, 1980). The classification of strategies into active or passive strategies is based on the individual's attitude to solve the stressful situation (Carver et al., 1989; Lazarus \& Folkman, 1984). Problem-focused coping refers to skills used to modify the problem or the stressor and include problem solving strategies. Meanwhile emotion-focused coping includes abilities to manage emotions that arise in stressful situations, such as us-

* Dirección para correspondencia [Correspondence address]:

Ramona Rubio Herrera. Departamento de Psicología Evolutiva y de la Educación. Facultad de Psicología. Universidad de Granada. Campus de la Cartuja s/n, 18071 Granada (Spain). E-mail: rrubioh@ugr.es
Abstract: The aim of this study was to evaluate the psychometric properties of the Coping Strategies Inventory (CSI) in a sample of 243 people aged 55 to 99 years old. The first order factorial structure was similar to the structure of the original version of the CSI and to the Spanish adaptation with general population. Furthermore, high levels of internal consistency and of convergent validity were observed in the different primary scales. Nevertheless, the problem avoidance scale did not surpass the validity and reliability tests. Due to it we propose to delete two of the items of this scale. On the other hand, in this study we confirmed the secondary and tertiary structure obtained in the original version of the inventory that was neither confirmed in the Spanish adaptation study nor the other studies on the psychometric properties of the Spanish version of the CSI.

Key words: CSI, coping, elderly, psychometric properties, Spanish version.

ing social support or self-control (Lazarus \& Folkman, 1984). Approach strategies include problem-focused and emotionfocused coping and aim at managing or transforming the stressful situation, while avoidance strategies refer to escaping the problem (Maddi, 1980). Classifying strategies into functional and dysfunctional coping depends on the situation, for a specific event a particular coping strategy might be functional while for another event the same coping strategy might be dysfunctional.

As a result of the different existing coping classifications there are many instruments that assess how people cope with demanding circumstances. The majority of these questionnaires have been adapted to the Spanish context. As such there are Spanish versions of the COPE inventory (Carver et al., 1989; Crespo \& Cruzado, 1997), the Coping Strategies Inventory (CSI) (Cano, Rodríguez, \& García, 2007; Tobin, Holroyd, Reynolds, \& Kigal, 1989), the adult form of Coping Responses Inventory (Kirchner, Forns, Muñoz, \& Pereda, 2008; Moos, 1993), the Coping Strategies Questionnaire (CAE) (Sandín \& Chorot, 2003) and of the Self-Efficacy Scale for Coping with Stress (EAEAE) (Godoy Izquierdo et al., 2008).

Of all these instruments, the CSI could be considered one of the most interesting because it provides information about several relevant aspects: the stressful event experienced by the participants, the frequency of use of eight primary coping strategies and the degree of perceived coping self-efficacy (Cano et al., 2007; Tobin et al., 1989).

The original CSI (Tobin et al., 1989) was developed from the Ways of Coping Scale (Folkman \& Lazarus, 1980). In order to develop the CSI, Tobin et al. (1989) followed Folkman and Lazarus's classification (1980) of problem-focused 
and emotion-focused strategies and Maddi's (1980) classification of approach or avoidance strategies.

The final version of CSI was validated using a sample of 398 university students and contained 72 items for eight primary strategies (nine items defined each strategy): problem solving, self-criticism, emotional expression, wishful thinking, social support, cognitive restructuring, problem avoidance and social withdrawal. The items of the CSI could also form four secondary strategies: problem focused engagement, problem focused disengagement, emotion focused engagement and emotion focused disengagement. Problems focused engagement includes problem solving and cognitive restructuring. Problem focused disengagement encompasses problem avoidance and wishful thinking strategies. Emotion focused engagement consists of emotional expression and social support strategies. Emotion focused disengagement comprises social withdrawal and self-criticism. Finally, the CSI inventory provides two tertiary strategies: engagement or disengagement strategies. Engagement contains both problem and emotion focused engagement strategies while other two secondary strategies problem and emotion focused disengagement are included in the disengagement category.

The Spanish version of the CSI was adapted and validated by Cano et al. (2007) in a sample of 337 participants age 17 to 55 years old from the province of Seville, Spain. The result of this adaptation was a reduced version of 40 items that showed high levels of internal consistency and adequate convergent validity. However, the secondary and tertiary structures obtained by Tobin et al. (1989) in the original version were not verifiable in the Spanish version tested by $\mathrm{Ca}$ no et al. (2007).

The psychometric properties of the Spanish version of the CSI (Cano et al., 2007) were also analyzed with two Mexican samples. In a first research, Nava, Ollua, Vega, and Soria (2010) applied the CSI to 219 participants with ages between 17 and 34 years old. The results of this study were similar to those obtained by Cano et al. (2007), although the reliability of the items was slightly higher. In addition, only the primary and tertiary structure could be confirmed in the study by Nava et al. (2010). The second investigation used imprisoned adults as a sample (Rodríguez-Díaz, EstradaPineda, Rodríguez-Franco, \& Bringas-Molleda, 2014). Similar results regarding the primary structure were found and the internal consistency of these scales was acceptable. However, the secondary and the tertiary structure of the CSI were neither confirmed in this sample.

To sum up, none of the studies that have attempted to validate the factorial structure of the Spanish version of the CSI has achieved to validate the secondary and the tertiary structure of the original version of the CSI. These previous studies only reproduced the primary structure of the CSI, thus the complete factorial structure of the Spanish version of the CSI has not been confirmed.

In addition, studying how people manage stressful events has been a very successful topic that is explored by different fields. The study of stressful events and how the elderly cope with them represent an important subject in the gerontological research (Villar, 1997). Aging is not a homogenous process (Ouwehand, De Ridder, \& Bensing, 2007) and it can vary depending on the individual's particular circumstances. Elderly people must cope with many age-specific stressful situations such as the loss of economic status due to retiring, increasing number of health problems or the loss of social network and widowhood (Krzemien, Urquijo, \& Monchietti, 2004; Martin, Kliegel, Rott, Poon, \& Johnson, 2008; Menninger, 1999; Urquijo, Monchietti, \& Krzemien, 2008). These circumstances could be perceived by some older adults as uncontrollable (Stefani \& Feldberg, 2006) and could dampen their well-being and mental health if they are not dealt with adequately (Villar, 1997). Nevertheless, these challenges do not uniformly hinder older people's well-being (Caprara \& Steca, 2005; Keyes, Shmotkin, \& Ryff, 2002) and this could be due to the fact that they count on internal resources (Bueno \& Navarro, 2003) which constitute protective mechanisms that might contribute to their resilience. Coping strategies can be counted among these protective mechanisms (Villar, Triadó, Solé, \& Osuna, 2003).

With regards to coping, the literature on aging shows that the use of the different coping strategies varies throughout the life span and that there are differences even between the young-old and the oldest-old (Martin et al., 2008; Meléndez, Mayordomo, Sancho, \& Tomás, 2012). Additionally aging involves a loss of personal resources and a reduction of available options; consequently secondary control and acceptance strategies become very relevant at this stage in life (Martin et al., 2008; Meléndez, Tomás, \& Navarro, 2007). Also in old age there is a high prevalence of physical and cognitive impairment that leads to frailty and loss of autonomy (Jylha, 2004) that might influence how older adults answer to coping inventories and scales. In addition, educational level of older participants is generally lower than in younger groups. Furthermore older people have less experience answering questionnaires which can also influence their responses. Because of the peculiarities of the elderly, instruments that were proved to be useful with other age groups might not be useful for assessing coping strategies used by older adults. Since the characteristics of this population group are significantly different from other age groups it is necessary to count on instruments that are specifically adapted with older adults. All this must be taken into account when exploring coping in old age. Thus, it is necessary to validate questionnaires to ensure that older people understand the items and answer them correctly.

However, despite the existing literature on coping in the elderly, only the CAE (Sandín \& Chorot, 2003) has been validated in the Spanish elderly population. In addition, none of the studies on the Spanish adaptation of the CSI included people age 62 or older. Therefore we consider it would be useful to study whether the CSI has good psychometric properties when used with older people.

The purpose of this study was to assess the psychometric properties of the CSI in a group of older people. In particu- 
lar in this study we aim at analyzing the primary, secondary and tertiary structure and the internal consistency (Cronbach's alpha) of the CSI in this age group. A confirmatory factor analysis approach was adopted.

\section{Method}

\section{Participants}

The sample of this study comprised 243 older adults, 82 males and 161 females, age 55 to 99 years old (mean age of 71.92 years; $S D=8.64$ ). The sample was selected from different elderly activity centres in Granada, Spain, using an intentional sampling. All the participants were literate and had elementary studies; none of the participants were included in the illiterate category. Furthermore, although the cognitive level was not assessed, the participants of this study were community-dwelling older adults who lead autonomous lives and attended activity centres. More information about the participants can be seen in Table 1 .

Table 1. Participants' characteristics.

\begin{tabular}{|c|c|}
\hline & $\begin{array}{c}\text { Total } \\
(N=243)\end{array}$ \\
\hline \multicolumn{2}{|l|}{ Gender } \\
\hline Men $(\%)$ & 33.7 \\
\hline Women $(\%)$ & 66.3 \\
\hline \multicolumn{2}{|l|}{ Age } \\
\hline Mean & 71.92 \\
\hline Range & $55-99$ \\
\hline$S D$ & 8.64 \\
\hline \multicolumn{2}{|l|}{ Age group } \\
\hline$<60(\%)$ & 6.2 \\
\hline $60-65(\%)$ & 18.1 \\
\hline $66-70(\%)$ & 21.8 \\
\hline $71-79(\%)$ & 35.8 \\
\hline$\geq 80(\%)$ & 18.1 \\
\hline \multicolumn{2}{|l|}{ Marital status } \\
\hline Single $(\%)$ & 10.7 \\
\hline Married (\%) & 50.2 \\
\hline Widowed (\%) & 30.9 \\
\hline Divorced (\%) & 6.2 \\
\hline New partner $(\%)$ & 2.1 \\
\hline \multicolumn{2}{|l|}{ Educational level } \\
\hline Elementary $(\%)$ & 50.6 \\
\hline Secondary $(\%)$ & 11.9 \\
\hline High school (\%) & 18.9 \\
\hline College $(\%)$ & 18.5 \\
\hline
\end{tabular}

\section{Instruments}

Socio-demographic characteristics. Questions regarding participants' age, gender, marital status and educational level were included in a semi-structured interview.

Coping Strategies. In order to assess the hierarchical structure of coping strategies the Spanish version of the CSI (Cano et al., 2007) was applied. This questionnaire is a reduced version of the original scale proposed by Tobin et al. (1989) that assesses three different aspects: the most recent stressful situation experienced by the participants, the coping strategies used to manage the situation they mentioned and the participants' coping self-efficacy. In order to inquire about a possible stressful circumstance that the interviewed has recently experienced an open question is first presented. To examine how the stressful event has been dealt with, participants have to answer 40 items that are rated on a five-point Likert scale $(0=$ not at all; $4=$ completely). Finally, in order to explore participants' coping self-efficacy a last item is included ("I consider that I can cope with the situation"). The original CSI scale by Tobin et al. (1989) had eight primary strategies grouped into four secondary and two tertiary strategies. The structure of the original version of the CSI can be seen in Figure 1. The first order structure explained $47 \%$ of the total variance and Cronbach's alpha reliability coefficients for the eight primary strategies ranged from .72 to .94 ; from .81 to .92 for the second ones; and finally, reliability for the tertiary strategies were .90 in engagement and .89 in disengagement (Tobin et al., 1989). In the Spanish adaptation of the inventory the first order structure explained $61 \%$ of the variance and Cronbach's alpha coefficients for the eight primary factors ranged from .63 and .89 (Cano et al., 2007).

\section{Procedure}

The questionnaire was filled in during a face-to-face interview by three trained interviewers. The interview lasted between 30 and 60 minutes and the interviewers read each question aloud and marked into the answering sheet the participant's answer. Older adults who volunteered to take part in the study were informed about the study characteristics (the purpose, the expected duration of the interview and the procedures) and were asked to sign the Informed Consent Form. Subsequently participants had to provide information on their socio-demographic characteristics, and answer the questions on coping.

\section{Data analysis}

To validate the hierarchical structure of the Spanish adaptation of the CSI, a series of confirmatory factor analyses were applied. Confirmatory Factor Analysis (CFA) is a technique that specifically deals with measurement models, that is, the relationships between observed measures or indicators and latent variables or factors. The application of this technique requires the researcher to have a firm a priori sense, based on past evidence and theory, of the number of factors that exist in the data and of what indicators are related to which factors (Brown, 2006). Confirmatory factor analysis (CFA) is a more powerful tool in the second stage of research when a model has already been established. When estimating the different confirmatory factor models we relied on the hierarchical structure of the CSI instrument proposed by Tobin et al. (1989). All confirmatory analyses were performed using Mplus 7.3 statistical package (Muthén \& 
Muthén, 1998/2012). Since in the analysed models indicators are ordinal in nature, we use WLSMV estimator (Byrne, 2012; Wang \& Wang, 2012). This is a robust estimator recommended when analysing categorical data (Finney \& DiStefano, 2013). The WLSMV estimator was developed by
Muthén, du Toit and Spisic (1997) and it was designed specifically to be applied with small and moderate sample sizes. Other statistical analyses were performed with SPSS statistical package (Verma, 2013)
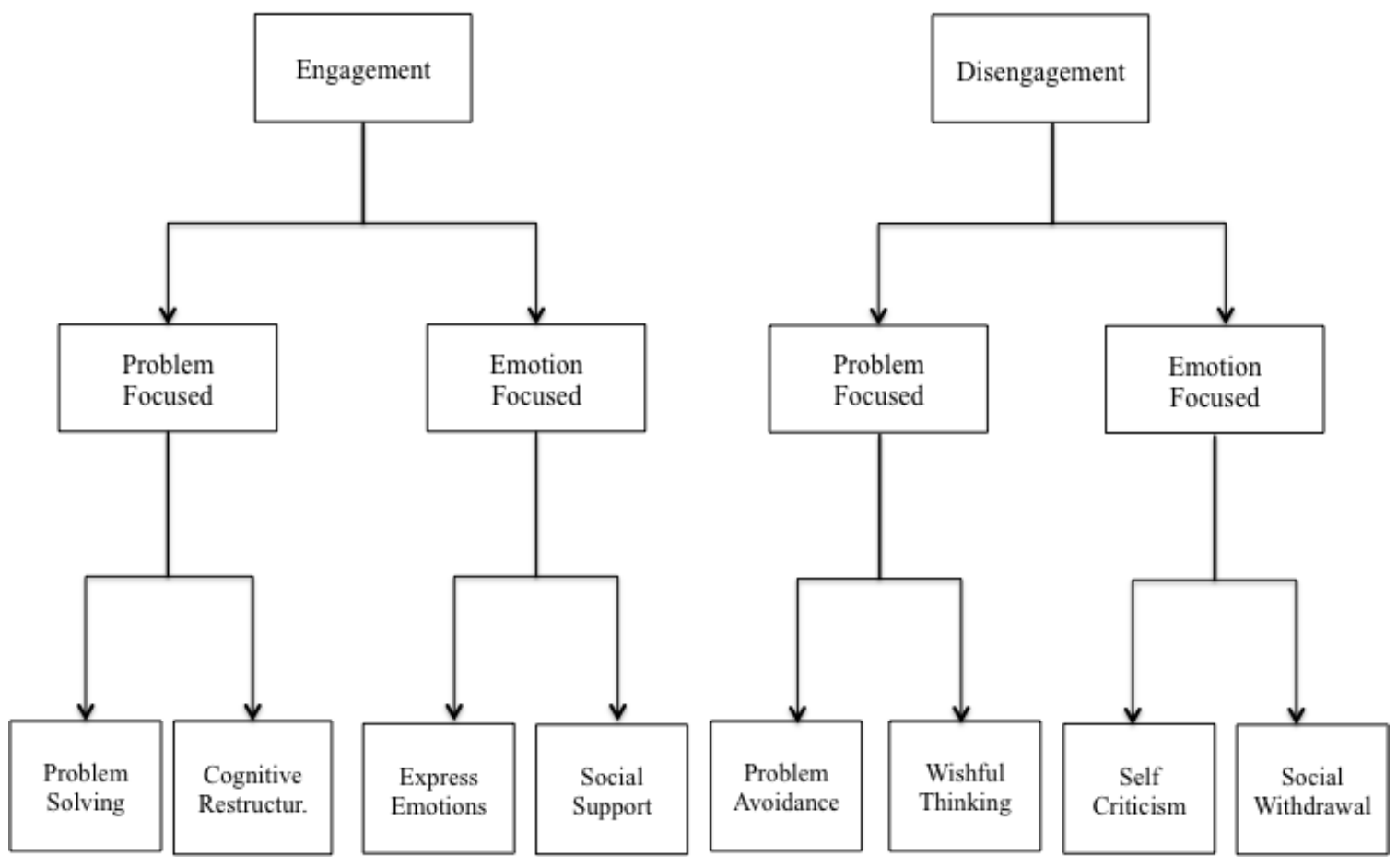

Figure 1. Hierarchical Factor Structure of CSI scale (Tobin et al., 1989).

With regards to the goodness of fit indicators for models we followed recommendations by Hair, Black, Babin, and Anderson (2014). Since in the secondary and tertiary structure the number of indicators is under 30 and sample size is greater than 250 cases, it was expected that the Chi-square Test was significant (see Table 2). In these cases, the use of a combined strategy of several indexes indicate that adjustment would be appropriate when the value of the indicator CFI and TLI is superior to .92, and also RMSEA take a value less than .07 (Hu \& Bentler, 1999; Hair et al., 2014).

Table 2. Recommended cut off values to assess goodness of fit of models \begin{tabular}{ll}
\hline Indices & Values for models with $12<\mathrm{m}<30$ and sample size
\end{tabular} Chi-Square Significant p-values expected

CFI or TLI Above.92

SRMR $\quad .08$ or less (with CFI above .92)

RMSEA $\quad$ Values $<.07$ with CFI of .92 or higher

Source: Hair et al. (2014), p. 584. $\mathrm{m}=$ number of observed variables

\section{Results}

\section{Second-order CFA models for engagement and dis- engagement coping strategies}

Before validating the tertiary structure of the CSI we conducted two second-order factor analyses. These analyses were aimed at validating both the secondary structure and the reliability of the eight primary scales. Our analysis included the four second-order factors proposed by Tobin et al. (1989) and we distinguished between engagement and disengagement strategies: a) Problem focused with engagement (eprobecen), b) Emotion focused with engagement (eemocen), c) Problem focused with disengagement (dprobcen), and e) Emotion focused with disengagement (democen). Figures $2 \mathrm{a}, 2 \mathrm{~b}$, Table 3 and Table 4 show the solutions obtained after models estimation. While the above mentioned figures show estimated standardized coefficients for the second-order confirmatory factor models, Tables 3 and 4 report information corresponding to measurement models (standardized solution, unstandardized solution and standards errors).

Table 3. WLSMV Estimates for Engagement strategies (Figure 2a). 


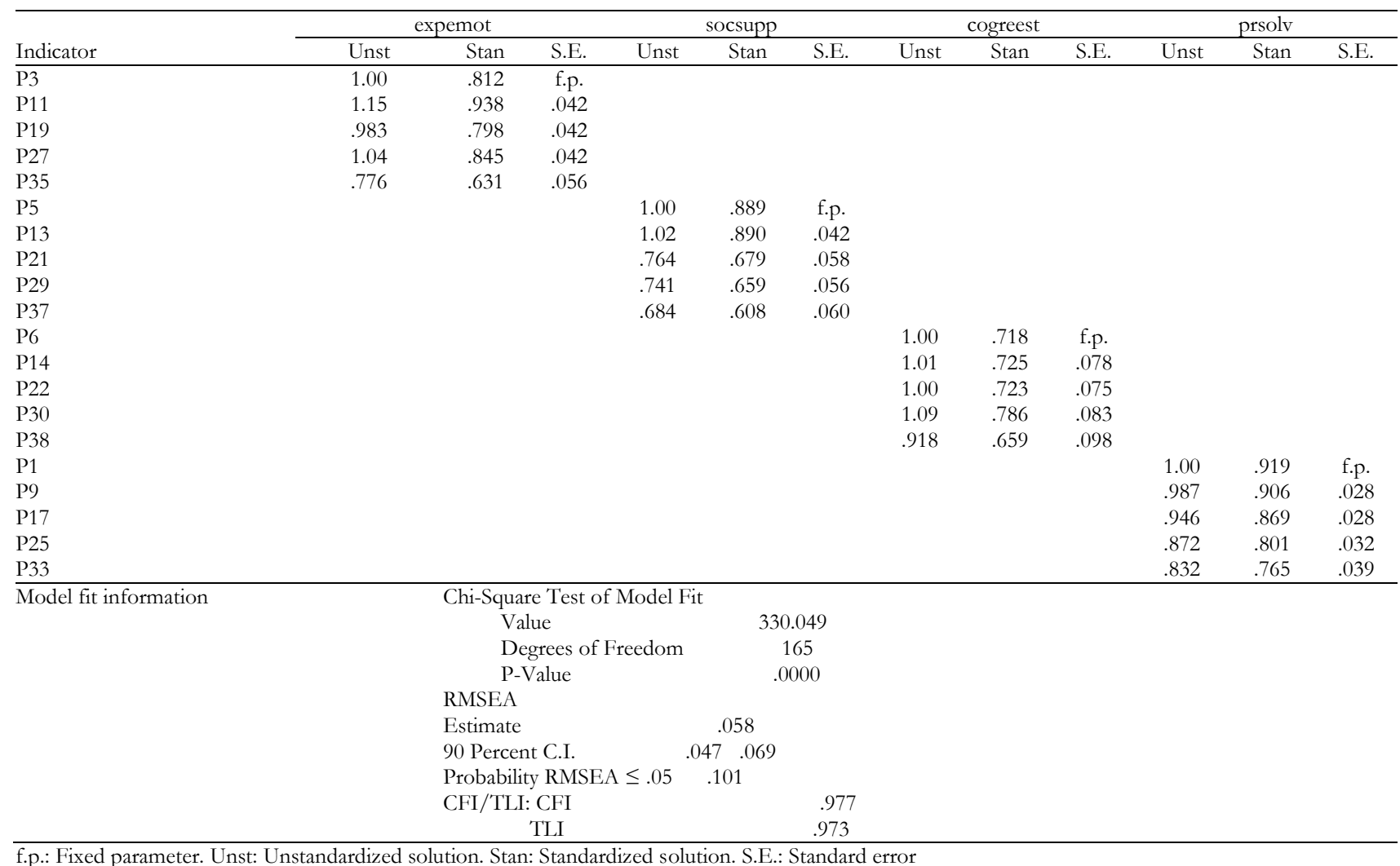

Table 4. WLSMV Estimates for Disengagement strategies (Figure 2b).

\begin{tabular}{|c|c|c|c|c|c|c|c|c|c|c|c|c|}
\hline \multirow[b]{2}{*}{ Indicator } & \multicolumn{3}{|c|}{ socwith } & \multicolumn{3}{|c|}{ selfcrit } & \multicolumn{3}{|c|}{ wisthink } & \multicolumn{3}{|c|}{ probav } \\
\hline & Unst & Stan & S.E. & Unst & Star & S.E. & Unst & Stan & S.E. & Unst & Stan & S.E. \\
\hline$\overline{\mathrm{P} 8}$ & 1.00 & .469 & f.p. & & & & & & & & & \\
\hline P16 & 1.42 & .668 & .184 & & & & & & & & & \\
\hline P24 & 1.73 & .813 & .234 & & & & & & & & & \\
\hline P32 & 1.67 & .782 & .228 & & & & & & & & & \\
\hline P40 & 1.80 & .847 & .245 & & & & & & & & & \\
\hline P2 & & & & 1.00 & .87 & f.p. & & & & & & \\
\hline P10 & & & & .881 & .77 & .046 & & & & & & \\
\hline P18 & & & & 1.05 & .92 & .041 & & & & & & \\
\hline P26 & & & & .968 & .84 & .038 & & & & & & \\
\hline P34 & & & & .970 & 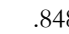 & .046 & & & & & & \\
\hline P4 & & & & & & & 1.00 & .835 & f.p. & & & \\
\hline P12 & & & & & & & 1.04 & .875 & .050 & & & \\
\hline P20 & & & & & & & 1.00 & .837 & .048 & & & \\
\hline P28 & & & & & & & .998 & .833 & .050 & & & \\
\hline P36 & & & & & & & .390 & .326 & .080 & & & \\
\hline P7 & & & & & & & & & & 1.00 & .537 & f.p. \\
\hline P15 & & & & & & & & & & 1.25 & .673 & .206 \\
\hline P23 & & & & & & & & & & 1.17 & .629 & .179 \\
\hline P31 & & & & & & & & & & 1.28 & .691 & .204 \\
\hline P39 & & & & & & & & & & .921 & .495 & .204 \\
\hline \multirow{10}{*}{ Model fit information } & \multicolumn{5}{|c|}{ Chi-Square Test of Model Fit } & \multirow[b]{2}{*}{322.844} & & & & & & \\
\hline & \multirow{2}{*}{\multicolumn{3}{|c|}{ Value }} & & & & & & & & & \\
\hline & & & & eedom & & 165 & & & & & & \\
\hline & \multicolumn{3}{|c|}{$\begin{array}{l}\text { Degrees of } \\
\text { P-Value }\end{array}$} & & & .0000 & & & & & & \\
\hline & \multirow{2}{*}{\multicolumn{3}{|c|}{$\begin{array}{l}\text { RMSEA } \\
\text { Estimate }\end{array}$}} & & & & & & & & & \\
\hline & & & & & & .057 & & & & & & \\
\hline & \multicolumn{3}{|c|}{90 Percent C.I. } & & .047 & .068 & & & & & & \\
\hline & \multicolumn{3}{|c|}{ Probability RMSI } & $\leq .05$ & .125 & & & & & & & \\
\hline & \multirow{2}{*}{\multicolumn{3}{|c|}{ CFI/TLI: CFI }} & & & .964 & & & & & & \\
\hline & & & & & & .958 & & & & & & \\
\hline
\end{tabular}

f.p.: Fixed parameter. Unst: Unstandardized solution. Stan: Standardized solution. S.E.: Standard error 


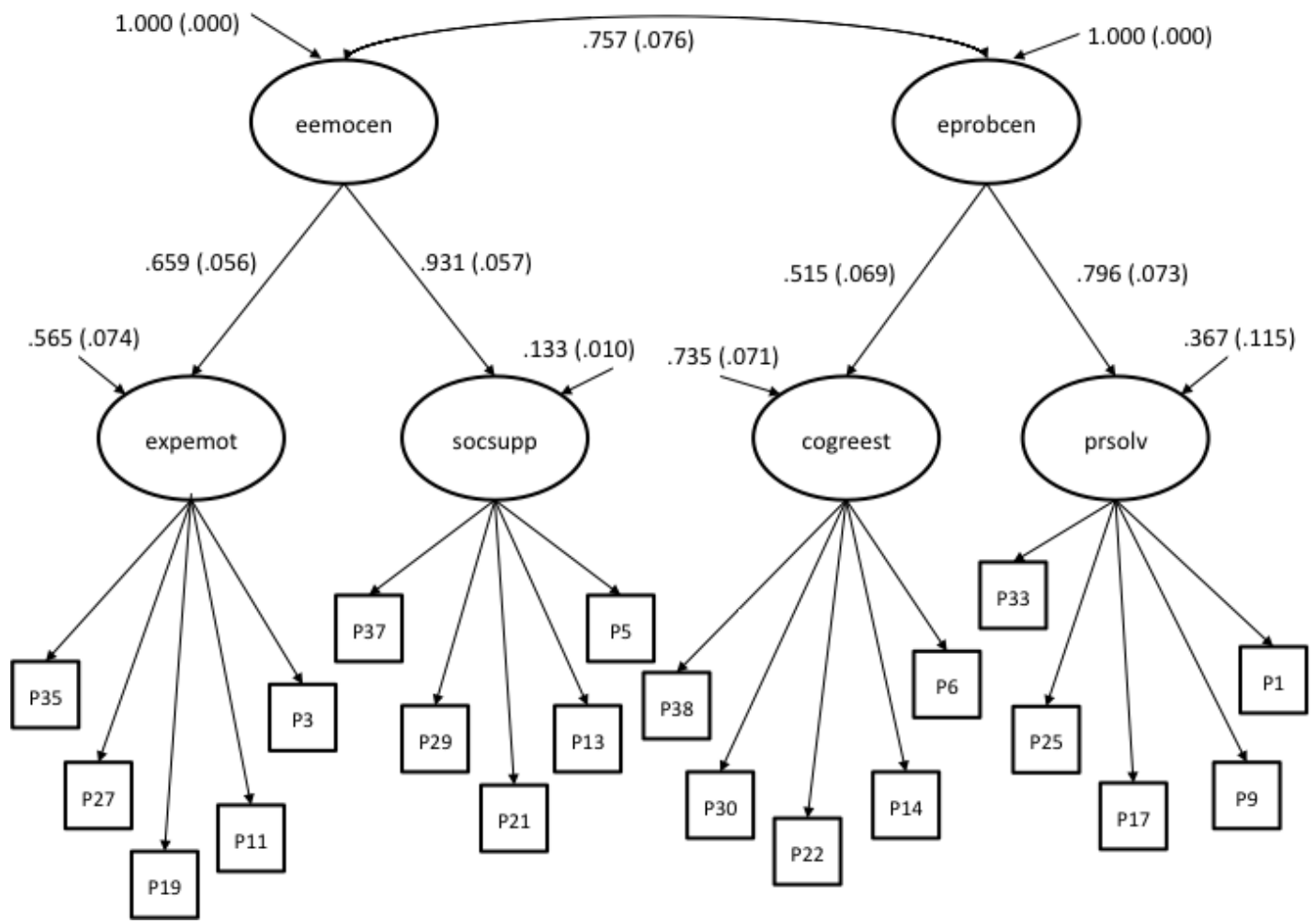

Figure 2a. Second order factor analysis for engagement strategies (standardized solution).

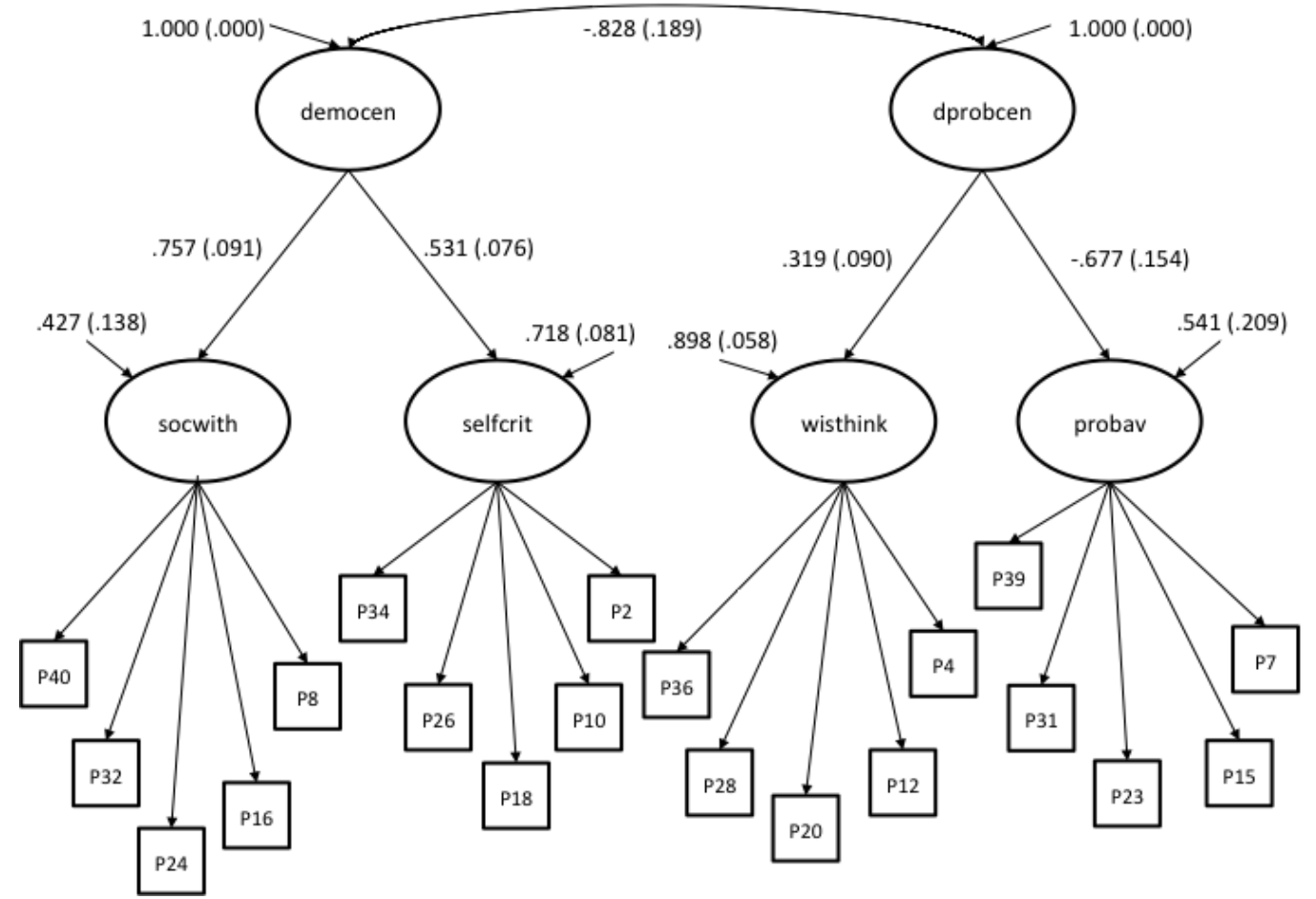

Figure 2b. Second order factor analysis for disengagement strategies (standardized solution). 


\section{Convergent validity}

In order to assess the convergent validity of the CSI we followed the proposal by Bagozzi, Yi, and Phillips (1991) that assumes convergent validity when the estimated factor loadings are statistically significant at $5 \%$. The $t$-value for significance of the parameters was obtained by dividing the unstandardized coefficient between the standard error. In all cases parameters were significant at least at $5 \%$ ( $t$-value $>$ 1.96 for a two-tailed test).

\section{Validity and reliability}

Following recommendations from the literature on validation technique using Confirmatory Factor Analysis (CFA), we calculated Construct Reliability (CR) and Average Variance Extracted (AVE) for every primary scale (Bagozzi \& Yi,
1988; Hair et al., 2014). Values close to or above 7 for composite reliability and .5 for average extracted variance were used as indicators of internal consistency of the scales (Bagozzi \& Yi, 1988; Hair et al., 2014). Results obtained in the validation of the eight primary scales can be seen in Table 5 . With exception of AVE for "Problem Avoidance" scale, all indicators exceeded minimum values recommended by the literature on the validity and reliability of scales. Similarly, except for "Problem Avoidance" scale Cronbach's alpha exceeded the minimum of .7 recommended in literature (Peterson, 1994). For "Problem Avoidance" scale the value of this coefficient (.651) was close to this limit, exceeding the minimum of $.5-.6$ recommended by Nunnally $(1967$, p.226) for a preliminary research. Thus, with the exception of "Problem Avoidance" scale, the scales that compose the primary order coping strategies seem to be valid and reliable.

Table 5. Validity and reliability of the primary scales.

\begin{tabular}{|c|c|c|c|c|c|}
\hline & Scales & Items & Construct Reliability (CR) & Average Variance Extracted (AVE) & Cronbach's alpha \\
\hline \multirow{4}{*}{\multicolumn{2}{|c|}{ 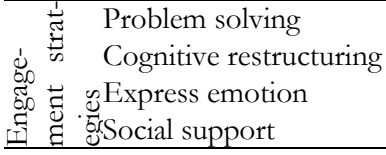 }} & $01+09+17+25+33$ & .9306 & .7295 & .888 \\
\hline & & $06+14+22+30+38$ & .8454 & .5232 & .787 \\
\hline & & $03+11+19+27+35$ & .9044 & .6576 & .869 \\
\hline & & $05+13+21+29+37$ & .8657 & .5695 & .795 \\
\hline \multirow{4}{*}{\multicolumn{2}{|c|}{ 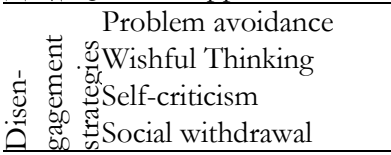 }} & $07+15+23+31+39$ & .7445 & .3719 & .651 \\
\hline & & $04+12+20+28+36$ & .8709 & .5927 & .758 \\
\hline & & $02+10+18+26+34$ & .9309 & .7301 & .879 \\
\hline & & $08+16+24+32+40$ & .8453 & .5312 & .726 \\
\hline
\end{tabular}

\section{Discriminant and nomological validity}

Table 6 shows the estimated correlation matrix for the latent variables linked to each of the primary coping strategies and displays information that allows us to check discriminant validity. One conservative approach for establishing discriminant validity compares the AVE estimates for each factor with the squared interconstruct correlations associated with that factor (Fornell \& Lacker, 1981). Again, except for "Problem avoidance", all AVE values estimated from Table 5 are greater than the corresponding interconstruct squared correlation estimates and, therefore, this test indicates that there are no problems with the discriminant validity for the confirmatory factor analysis of the model. Results from Table 6 also indicate that there is a nomological validity of the model because, as shown by the literature (Nava et al., 2010; Rodríguez-Díaz et al., 2014), the correlations among the constructs have the expected sign. Except for the cognitive restructuring and the wishful thinking strategies, that were positively correlated, in general coping strategies grouped in the Engagement factor negatively correlate with the Disengagement factor strategies. Similarly, the emotion focused strategies of the Engagement factor are negatively associated with the emotion focused strategies of the Disengagement factor. Meanwhile the problem solving strategy positively correlates with all the other strategies.

$\underline{\text { Table 6. Correlation matrix and squared correlations (shared variance) for the primary scales. }}$

\begin{tabular}{|c|c|c|c|c|c|c|c|c|}
\hline & 1 & 2 & 3 & 4 & 5 & 6 & 7 & 8 \\
\hline 1. Problem solving & 1.00 & .167 & .295 & .177 & .007 & .207 & .000 & .093 \\
\hline 2. Cognitive restructuring & .409 & 1.00 & .165 & .038 & .499 & .000 & .012 & .002 \\
\hline 3. Social support & .544 & .407 & 1.00 & .381 & .000 & .076 & .025 & .289 \\
\hline 4. Express emotions & .421 & .197 & .618 & 1.00 & .028 & .133 & .006 & .356 \\
\hline 5. Problem avoidance & -.087 & .707 & -.020 & -.169 & 1.00 & .046 & .069 & .182 \\
\hline 6. Wishful thinking & .455 & .056 & .277 & .366 & -.215 & 1.00 & .029 & .027 \\
\hline 7. Self criticism & -.059 & .112 & -.161 & -.083 & .264 & -.171 & 1.00 & .160 \\
\hline 8. Social withdrawal & -.306 & -.046 & -.538 & -.597 & .427 & -.166 & .401 & 1.00 \\
\hline Averag. Varianc. Extr. (AVE) & .729 & .523 & .569 & .657 & .371 & .592 & .730 & .531 \\
\hline
\end{tabular}

Note: Correlations with values greater than .15 are statistically significant (at least $5 \%$ ). Values below the diagonal are correlation estimates among the constructs, and values above diagonal are squared correlations (shared variance). 
"Problem Avoidance" scale purification

Since "Problem avoidance" scale seems to present problems in terms of its validity and internal consistency, we conducted additional analyses that allow us to decide whether to eliminate items P7 and P39 or not. Specifically, both P7 and P39 items showed relatively low standardized loadings, high standardized residuals (greater than 4 in absolute values) and low individual reliabilities (Hair et al., 2014; Sharma, 1996). After removing these items from the "Problem avoidance" scale, construct reliability was .7497 and average variance extracted .5008. Also, removing these two items does not adversely affect the estimated loadings for the remaining measurement scales. With this change, all recommendations from the literature on measurement scales validity and reliability are met.

\section{Tertiary hierarchical structure}

After verifying that the hierarchical structure of the second level was valid, we conducted two additional confirmatory factor analyses that intended to verify the tertiary hierarchical structure. The first analysis was conducted for the engagement strategies, and the second one for the disengagement strategies (the "Problem avoidance" scale consists of only three items). While Figures $3 \mathrm{a}$ and $3 \mathrm{~b}$ show the standardized solution obtained after estimation using WLSMV estimator, Table 7 presents information that allows us to assess the goodness of fit of the models of the tertiary structure.

Again we noted that, given the characteristics of our model with under thirty indicators and a sample size of more than 250 cases, the goodness of fit indices show that both models have a proper fit. Although the Chi-square Tests were significant, RMSEA, TLI RMSEA and GFI values exceed minimum levels recommended for an acceptable fit (Hair et al., 2014).

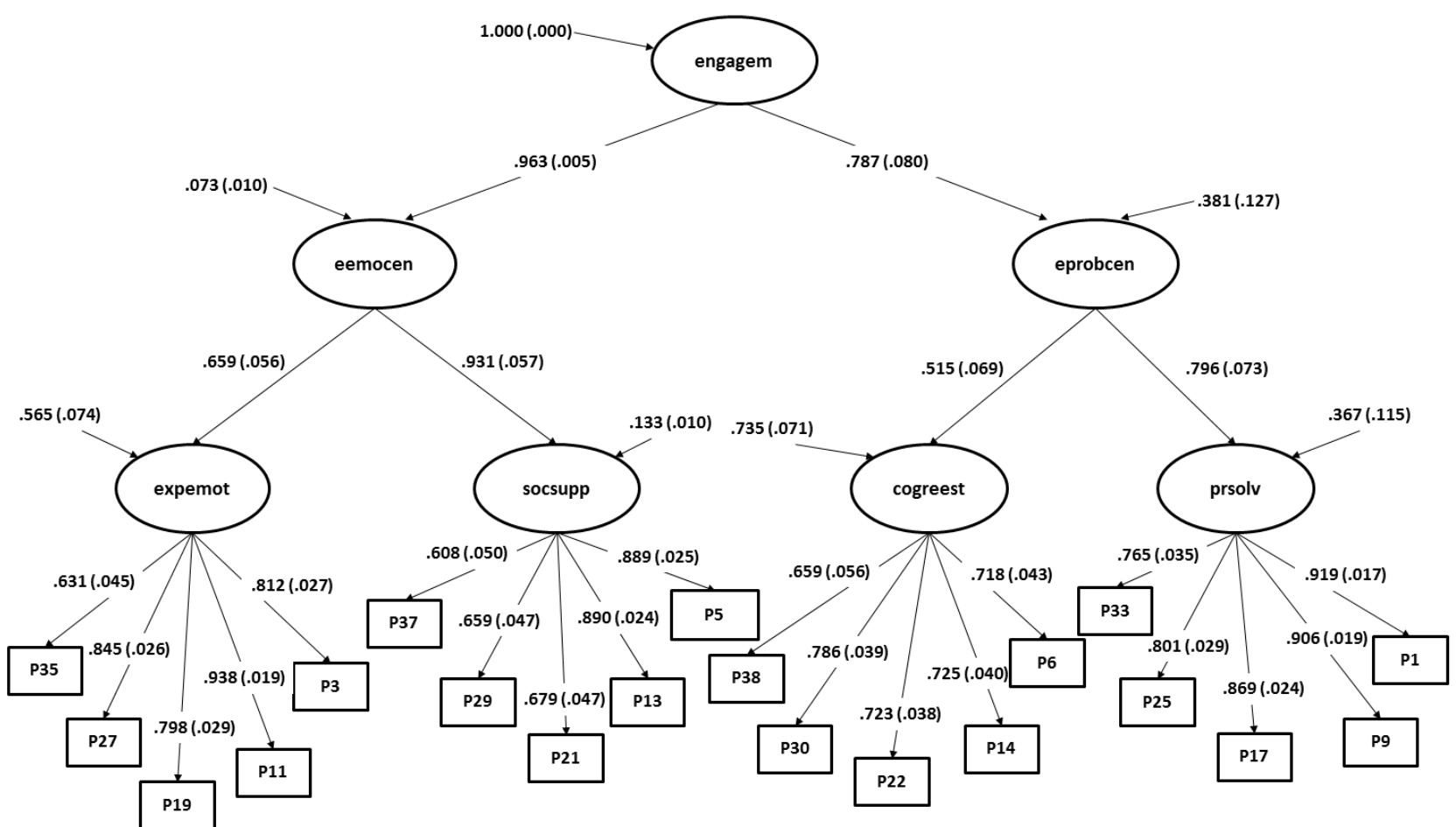

Figure 3a. Tertiary hierarchical structure for engagement strategies (standardized solution) 


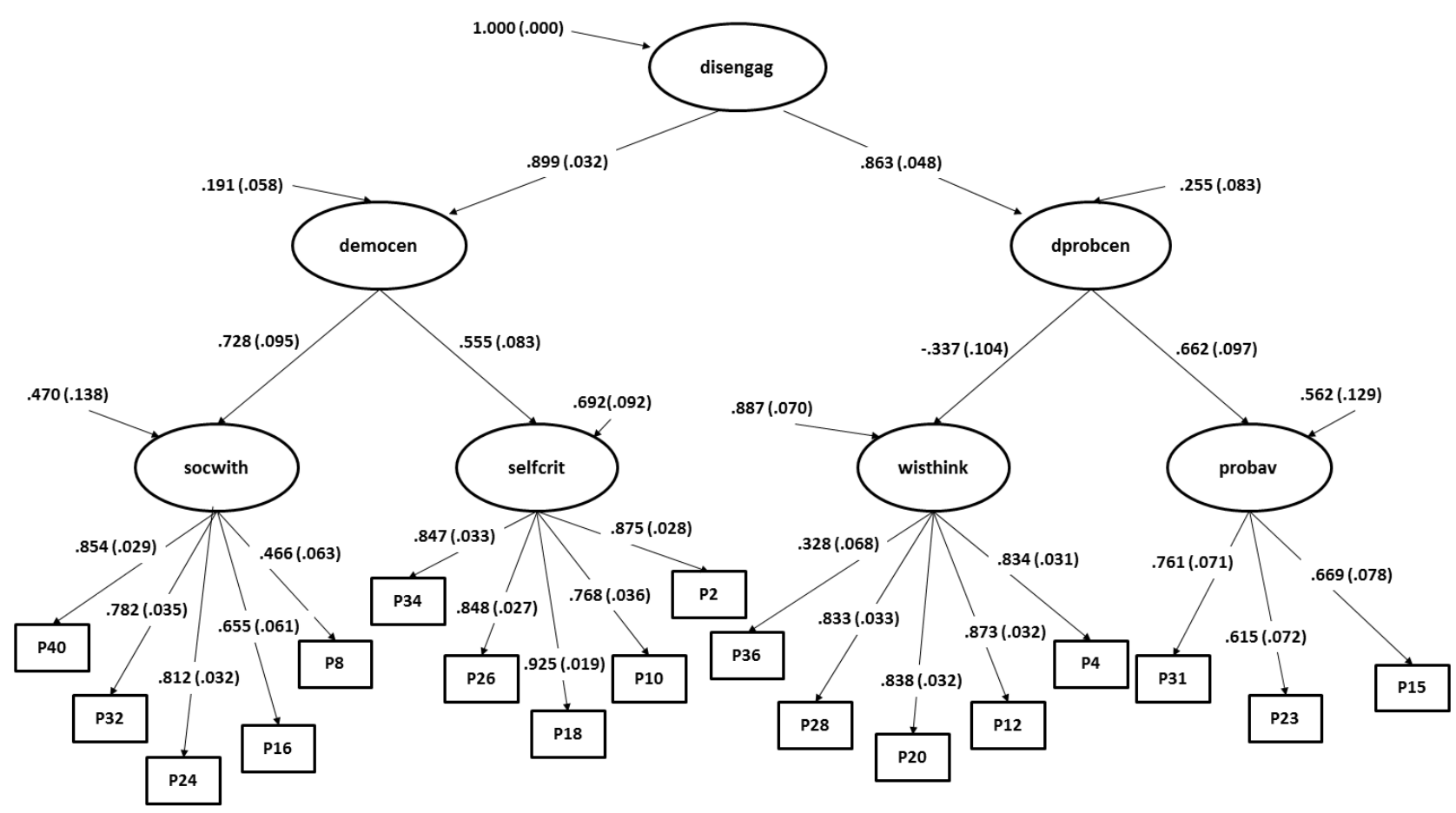

Figure 3b. Tertiary hierarchical structure for disengagement strategies (standardized solution)

Table 7. Indicators of goodness of fit for models of the tertiary structure.

\begin{tabular}{|c|c|c|}
\hline \multirow{2}{*}{\multicolumn{2}{|c|}{$\begin{array}{l}\text { Engagement } \\
\text { Chi-Square Test of Model Fit }\end{array}$}} & Disengagement \\
\hline & & Chi-Square Test of Model Fit \\
\hline Value & 330.049 & 267.420 \\
\hline Degrees of Freedom & 165 & Degrees of Freedom \\
\hline P-Value & .0000 & P-Value \\
\hline RMSEA & & RMSEA \\
\hline Estimate & .064 & Estimate \\
\hline 90 Percent C.I. & $4 \quad .074$ & 90 Percent C.I. \\
\hline Probability RMSEA $\leq .05$ & $5 \quad .012$ & Probability RMSEA $\leq .05 .013$ \\
\hline CFI/TLI & & CFI/TLI \\
\hline CFI & 972 & .961 \\
\hline TLI & .968 & 955 \\
\hline
\end{tabular}

\section{Discussion}

The purpose of this study was to evaluate the psychometric properties of the CSI in a group of older people. In particular in this study we aimed at analyzing the primary, secondary and tertiary structure of the CSI using a confirmatory factor analysis approach.

Among the available inventories that measure coping strategies the CSI, proposed by Tobin et al. (1989), is one of the most widely accepted instruments. The different studies on the adaptation of the short version of the CSI (consisting of forty items) have shown that this scale has acceptable reliability and validity (Cano et al., 2007; Nava et al., 2010; Rodríguez-Díaz et al., 2014). Nevertheless these studies have not been able to confirm the secondary and the tertiary structure of the original version of the CSI (Tobin et al., 1989). Because of it we considered it was necessary to perform a confirmatory factor analysis and in this way to confirm the hierarchical structure of the CSI originally proposed by Tobin et al. (1989) in the reduced version of the Spanish adaptation by Cano et al. (2007).

Furthermore the CSI has been validated with diverse samples and in different cultural settings (Cano et al., 2007; Martin et al., 2008; Moos, Brennan, Schutte, \& Moos, 2006; Nava et al., 2010; Rodríguez-Díaz et al., 2014). However since we are not aware of the existence of studies that have validated this scale in older people, we were interested in verifying the validity and the reliability of this questionnaire with older adults. The studies we have identified on the Spanish adaptation have exclusively tested the psychometric properties and the factorial structure with adults that have not reached old age. It is important to validate instruments in samples of older adults and especially inventories that measure coping strategies because the elderly have to deal with stressful events and life circumstances that are substantially different from those that younger adults have to cope with (Krzemien et al., 2004; Martin et al., 2008; Menninger, 1999; Ouwehand et al., 2007; Urquijo et al., 2008; Villar, 1997). Thus the present study is the first one in verifying the validity and the reliability of the CSI in an elderly sample.

Firstly, the correlations we observed between different strategies were as expected in the literature (Nava et al., 2010; Rodríguez-Díaz et al., 2014). Positive correlations were 
found between the engagement factor, problem solving, cognitive restructuring, social support and express emotion. Meanwhile these strategies negatively correlated with the disengagement factor strategies, problem avoidance, selfcriticism and with social withdrawal.

Through the different analyses we were able to confirm that seven of the eight coping strategies scales initially proposed by Cano et al. (2007) show high validity and reliability when analysed in a sample of older adults. Therefore this instrument is adequate to measure coping strategies in the elderly. Nevertheless the analyses performed showed that the problem avoidance scale, which in the version by Cano et al. (2007) comprised items 7, 15, 23, 31 and 39, do not surpass the test that allow us to conclude that the scale is valid and reliable. In this way, in order for the scale to meet the validity and reliability criteria recommended in the confirmatory factor analyses literature we considered it was necessary to eliminate items 7 and 39. Although in English these two items are not very similar ("I didn't let it get to me; I refused to think about it too much"- item 7 and "I avoided thinking or doing anything about the situation"-item 39) the Spanish translation of two items is almost identical "No dejé que me afectara; evité pensar en ello demasiado" - for item 7 and "Evité pensar o hacer nada" - for item 39). The similarity of these two items in Spanish or the translation of these two items from English could have been responsible that they are not properly understood by the elderly. On the other hand, in both the original version and the Spanish adaptation the problem avoidance scale had the lowest Cronbach's alpha value, .72 and .63 respectively. Therefore, it might be that the problems with this scale may come from the original version. Due to it we believe it is necessary to perform more into depth analyses when studying the factorial structure of the CSI in a sample of older adults. In this way it is possible to modify the items that are not properly understood by the elderly.

With regards to the hierarchical structure of the original proposed by Tobin et al. (1989), unlike in the previous studies on the Spanish adaptation the CSI (Cano et al., 2007; Nava et al., 2010; Rodríguez-Díaz et al., 2014), in the present study we were able confirm that, in this elderly sample, the reduced version of the CSI, presents a hierarchical factorial

\section{References}

Bagozzi, R. P., \& Yi, Y. (1988). On the evaluation of structural equation models. Journal of the Academy of Marketing Science, 16(1), 74-94. doi: 10.1007/BF02723327

Bagozzi, R. P., Yi, Y., \& Phillips, L. W. (1991). Assessing construct validity in organizational research. Administrative Science Quarterly,36(3), 421-458. doi: $10.2307 / 2393203$

Brown, T. A. (2006). Confirmatory factor analysis for applied research. New York: Guilford Press.

Bueno, B., \& Navarro, A. B. (2003). Identificación de los problemas, afrontamiento y relación con la satisfacción vital en personas muy mayores. Mapfre Medicina, 14(1), 37-50.

Byrne, B. M. (2012). Structural equation modeling with Mplus: Basic concepts, applications, and programming. New York: Routledge. structure that comprises eight primary scales. We also confirmed the secondary and tertiary structures of the original version of the scale. Thus the results regarding the structure of the inventory when it is applied to older people differ from those obtained with younger people in Spain. This shows that it is necessary to confirm that inventories are adequate to be used with older adults and that it is required to analyze the validity and reliability of measures in this age group.

On the other hand, it is possible that the differences in results obtained when analyzing the CSI structure with elderly sample and with younger samples could be explained by the different proportion of male and female in each sample; in the Spanish adaptation study of the CSI the sample comprised mainly men, while the sample of older people that we used in this study consisted mainly of women, as it occurred in the original version of Tobin et al. (1989). Since men and women do not interpret stressful situations in the same way, the composition of the sample could be responsible for the differences in the results of the hierarchical structure. Therefore the present study contributes to confirming the structure of the CSI in the Spanish elderly and to acknowledging that the Spanish adaptation of the short version of the CSI is adequate for studying coping strategies in Spanish older adults. However, although the sample was mainly composed by older people, there is a small number of participants who are not considered elderly from a biological (60 years) or a legal (65 year) perspective, hence it would be interesting to replicate this study with a sample of individuals whose age exceeded these limits. In addition, considering that in this study the size of the sample was half of the size of the sample of other studies that have validated this instrument (Cano et al., 2007; Tobin et al., 1989), future studies should focus on representative, more diverse samples of older adults from different regions in Spain.

The results of this study indicate that problematic items of the CSI should be analyzed more into depth. Also the type of stressful situation that more commonly older adults have to deal with should also be also analyzed. Finally future studies should also explore if the copings strategies used by the elderly vary depending on the stressful situation they have to face.

Cano, F. J., Rodríguez, L., \& García, J. (2007). Spanish version of the Coping Strategies Inventory. Actas Españolas De Psiquiatría, 35(1), 29-39.

Caprara, G. V., \& Steca, P. (2005). Affective and social self-regulatory efficacy beliefs as determinants of positive thinking and happiness. European Psychologist, 10(4), 275-275-286. doi: 10.1027/10169040.10.4.275

Carver, C. S., Scheier, M. F., \& Weintraub, J. K. (1989). Assessing coping strategies: A theoretically based approach. Journal of Personality and Social Psychology, 56(2), 267-283. doi: 10.1037/0022-3514.56.2.267

Crespo, M., \& Cruzado, J. (1997). La evaluación del afrontamiento: Adaptación española del cuestionario COPE con una muestra de estudiantes universitarios. Análisis y Modificación de Conducta, 23(92), 797-830. 
Englbrecht, M., Gossec, L., DeLongis, A., Scholte-Voshaar, M., Sokka, T., Kvien, T. K., \& Schett, G. (2012). The impact of coping strategies on mental and physical well-being in patients with rheumatoid arthritis. Seminars in Arthritis and Rheumatism,41(4), 545-555. doi: 10.1016/j.semarthrit.2011.07.009

Finney, S. J., \& DiStefano, Ch. (2013). Nonnormal and categorical data in structural equation modeling, in G.R. Hancock, \& R.O. Mueller, Structural Equation Modeling. A second course (2nd ed.) (pp.439-492). Charlotte, NC: Information Age Publishing.

Folkman, S. (1984). Personal control and stress and coping processes: A theoretical analysis. Journal of Personality and Social Psychology, 46(4), 839852. doi: $10.1037 / 0022-3514.46 .4 .839$

Folkman, S., \& Lazarus, R. S. (1980). An analysis of coping in a middleaged community sample. Journal of Health and Social Behavior, 21(3), 219239. doi: $10.2307 / 2136617$

Fornell, C., \& Larcker, D. F. (1981). Evaluating structural equation models with unobservable variables and measurement error. Journal of Marketing Research, 18(1), 39-50. doi: 10.2307/3151312

Godoy Izquierdo, D., Godoy García, J. F., López-Chicheri Garcia, I., Martínez Delgado, A., Gutiérrez Jiménez, S., \& Vázquez Vázquez, L. (2008). Propiedades psicométricas de la Escala de Autoeficacia para el Afrontamiento del Estrés (EAEAE). Psicothema, 20(1), 155-165.

Gustems-Carnicer, J. G., \& Calderón, C. (2013). Coping strategies and psychological well-being among teacher education students: Coping and well-being in students. European Journal of Psychology of Education, 28(4), 1127-1140. doi: 10.1007/s10212-012-0158-x

Hair, J. F., Black, W. C, Babin, B. J., \& Anderson, R. E. (2014). Multivariate data analysis. NewYork: Pearson Prentice Hall.

Hu, L. T., \& Bentler, P. M. (1999). Cutoff criteria for fit indexes in covariance structure analysis: Conventional criteria versus new alternatives. Structural Equation Modeling: A Multidisciplinary Journal, 6(1), 1-55. doi: $10.1080 / 10705519909540118$

Jylha, M. (2004). Old age and loneliness: Cross-sectional and longitudinal analyses in the Tampere longitudinal study on aging. Canadian Journal on Aging, 23(2), 157-68. doi: 10.1353/cja.2004.0023

Keyes, C. L. M., Shmotkin, D., \& Ryff, C. D. (2002). Optimizing wellbeing: The empirical encounter of two traditions. Journal of Personality and Social Psychology, 82(6), 1007-1022. doi: 10.1037/00223514.82.6.1007

Kirchner, T., Forns, M., Muñoz, D., \& Pereda, N. (2008). Psychometric Properties and Dimensional Structure of Coping Responses Inventory Adult Form. Psicothema, 20(4), 902-909.

Krzemien, D., Urquijo, S., \& Monchietti, A. (2004). Aprendizaje social y estrategias de afrontamiento a los sucesos críticos del envejecimiento femenino. Psicothema 16(3), 350-356.

Lazarus, R. S., \& Folkman, S. (1984). Stress, appraisal, and coping. New York: Springer.

Maddi, S. R. (1980). Personality as a resource in stress resistance. Paper presented at the meeting of the American Psychological Association, Montreal.

Martin, P., Kliegel, M., Rott, C., Poon, L. W., \& Johnson, M. A. (2008). Age differences and changes of coping behavior in three age groups: Findings from the Georgia Centenarian Study. The International Journal of $A g$ ing and Human Development, 66(2), 97-114. doi: 10.2190/AG.66.2.a

Meléndez, J. C., Mayordomo, T., Sancho, P., \& Tomás, J. M. (2012). Coping strategies: Gender differences and development throughout life span. The Spanish Journal of Psychology, 15(3), 1089-1098. doi: 10.5209/rev_SJOP.2012.v15.n3.39399

Meléndez, J. C., Tomás, J. M., \& Navarro, E. (2007). Análisis de las redes sociales en la vejez a través de la entrevista Manhein de apoyo social. Salud Pública de México, 49(6), 408-414.
Menninger, W. W. (1999). Adaptational challenges and coping in late life. Bulletin of the Menninger Clinic, 63(2), 4-15.

Moos, R. H. (1993). Coping Responses Inventory: CRI Adult Form. Professional Manual. Odessa: Psychological Assessment Resources.

Moos, R. H., Brennan, P. L., Schutte, K. K., \& Moos, B. S. (2006). Older adults' coping with negative life events: Common processes of managing health, interpersonal, and financial/work stressors. The International Journal of Aging and Human Development, 62(1), 39-59. doi: 10.2190/ENLH-WAA2-AX8J-WRT1

Muthén, B. O., du Toit, S. H. C., \& Spisic, D. (1997). Robust inference using weighted least squares and quadratic estimating equations in latent variable modeling with categorical and continuous outcomes (Unpublished technical report). Los Angeles: University of California. Retrieved from http://www.statmodel.com/bmuthen/articles/Article_075.pdf

Muthén, L. K., \& Muthén, B. O. (1998/2012). Mplus User's Guide (7th ed.). Los Angeles, CA: Muthén \& Muthén.

Nava, C., Ollua, P., Vega, C., \& Soria, R. (2013). Inventario de estrategias de afrontamiento: Una replicación. Psicología y Salud, 20(2), 213-220.

Nunnally, J. C. (1967). Psychometric Theory (1st ed.). New York: MacGrawHill.

Ouwehand, C., De Ridder, D., \& Bensing, J. (2007). A review of successful aging models: Proposing proactive coping as an important additional strategy. Clinical Psychology Review, 27(8), 873-884. doi: 10.1016/j.cpr.2006.11.003

Peterson, R. A. (1994). A meta-analysis of Cronbach's coefficient alpha. Journal of Consumer Research, 21(2), 381-391.

Rodríguez-Díaz, F. J., Estrada-Pineda, C., Rodríguez-Franco, L., \& BringasMolleda, C. (2014). Adaptación del inventario de estrategias de afrontamiento (CSI) a la población penitenciaria de México. Psicologia: Reflexão e Crítica, 27(3), 415-423. doi: 10.1590/1678-7153.201427301

Sandín, B., \& Chorot, P. (2003). Cuestionario de afrontamiento del estrés (CAE): desarrollo y validación preliminar. Revista de Psicopatología y Psicología Clínica, 8(1), 39-54. doi: 10.5944/rppc.vol.8.num.1.2003.3941

Sharma, S. (1996). Applied multivariate techniques. New York: John Wiley \& Sons, Inc.

Skinner, E. A., Edge, K., Altman, J., \& Sherwood, H. (2003). Searching for the structure of coping: A review and critique of category systems for classifying ways of coping. Psychological Bulletin, 129(2), 216-269. doi: 10.1037/0033-2909.129.2.216

Stefani, D., \& Feldberg, C. (2006). Estrés y estilos de afrontamiento en la vejez: Un estudio comparativo en senescentes argentinos institucionalizados y no institucionalizados. Anales de psicología, 22(2), 267-272. doi: $10.6018 / 25951$

Tobin, D. L., Holroyd, K. A., Reynolds, R. V., \& Wigal, J. K. (1989). The hierarchical factor structure of the coping strategies inventory. Cognitive Therapy and Research, 13(4), 343-361. doi: 10.1007/BF01173478

Urquijo, S., Monchietti, A., \& Krzemien, D. (2008). Adaptación a la crisis vital del envejecimiento: Rol de los estilos de personalidad y de la apreciación cognitiva en adultas mayores. Anales de Psicología, 24(2), 299-311. doi: $10.6018 / 42841$

Verma, J. P. (2013). Data analysis in management with SPSS software. London: Springer

Villar, F. (1997). Estrategias para afrontar el envejecimiento y diferencias asociadas a la edad: Una aproximación a través del análisis de contenido. Anuario de Psicología, 73, 57-69.

Villar, F., Triadó, C., Solé, C., \& Osuna, M. (2003). Bienestar, adaptación y envejecimiento: Cuando la estabilidad significa cambio. Revista Multidisciplinar de Gerontología, 13(3), 152-162.

Wang, J., \& Wang, X. (2012). Structural equation modeling: Applications using Mplus. Chichester: John Wiley \& Sons.

(Article received: 30-12-2014; revised: 08-07-2015; accepted: 24-03-2015) 